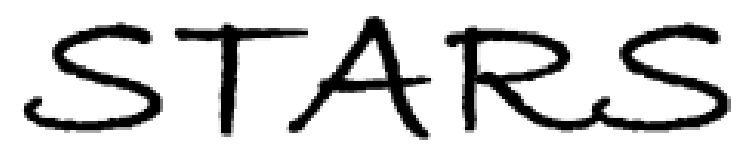

University of Central Florida

STARS

$1-1-2015$

\title{
A thermodynamic interpretation of Budyko and L'vovich formulations of annual water balance: Proportionality Hypothesis and maximum entropy production
}

\author{
Dingbao Wang \\ University of Central Florida \\ Jianshi Zhao \\ Yin Tang \\ University of Central Florida \\ Murugesu Sivapalan
}

Find similar works at: https://stars.library.ucf.edu/facultybib2010

University of Central Florida Libraries http://library.ucf.edu

This Article is brought to you for free and open access by the Faculty Bibliography at STARS. It has been accepted for inclusion in Faculty Bibliography 2010 s by an authorized administrator of STARS. For more information, please contactSTARS@ucf.edu.

\section{Recommended Citation}

Wang, Dingbao; Zhao, Jianshi; Tang, Yin; and Sivapalan, Murugesu, "A thermodynamic interpretation of Budyko and L'vovich formulations of annual water balance: Proportionality Hypothesis and maximum entropy production" (2015). Faculty Bibliography 2010s. 6854.

https://stars.library.ucf.edu/facultybib2010/6854

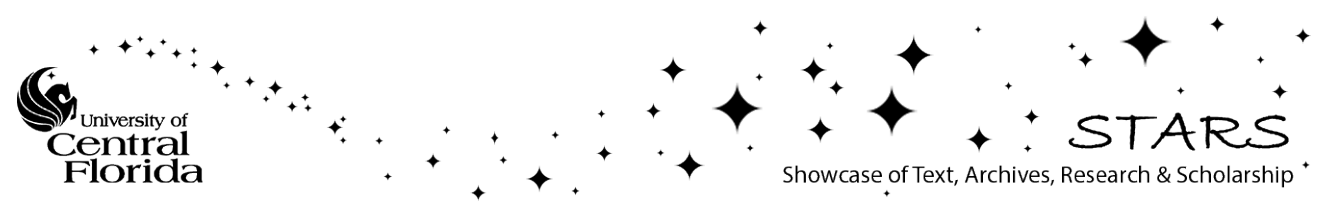




\section{Water Resources Research}

\section{TECHNICAL REPORTS: METHODS}

10.1002/2014WR016857

Key Points:

- Thermodynamic interpretation of

Budyko Curve and L'vovich

formulation

- Derive proportionality hypothesis

from maximum entropy production

Correspondence to:

D. Wang,

dingbao.wang@ucf.edu

Citation:

Wang, D., J. Zhao, Y. Tang, and

M. Sivapalan (2015), A thermodynamic

interpretation of Budyko and L'vovich

formulations of annual water balance:

Proportionality Hypothesis and

maximum entropy production, Water

Resour. Res., 51, 3007-3016,

doi:10.1002/2014WR016857.

Received 29 DEC 2014

Accepted 4 APR 2015

Accepted article online 8 APR 2015

Published online 26 APR 2015

\section{A thermodynamic interpretation of Budyko and L'vovich formulations of annual water balance: Proportionality Hypothesis and maximum entropy production}

\author{
Dingbao Wang', Jianshi Zhao'2, Yin Tang', and Murugesu Sivapalan 3,4 \\ ${ }^{1}$ Department of Civil, Environmental, and Construction Engineering, University of Central Florida, Orlando, Florida, USA, \\ ${ }^{2}$ State Key Laboratory of Hydro-Science and Engineering, Department of Hydraulic Engineering, Tsinghua University, \\ Beijing, China, ${ }^{3}$ Department of Geography and Geographic Information Science, University of Illinois at Urbana- \\ Champaign, Urbana, Illinois, USA, ${ }^{4}$ Department of Civil and Environmental Engineering, University of Illinois at Urbana- \\ Champaign, Urbana, Illinois, USA
}

\begin{abstract}
The paper forms part of the search for a thermodynamic explanation for the empirical Budyko Curve, addressing a long-standing research question in hydrology. Here this issue is pursued by invoking the Proportionality Hypothesis underpinning the Soil Conservation Service (SCS) curve number method widely used for estimating direct runoff at the event scale. In this case, the Proportionality Hypothesis posits that the ratio of continuing abstraction to its potential value is equal to the ratio of direct runoff to its potential value. Recently, the validity of the Proportionality Hypothesis has been extended to the partitioning of precipitation into runoff and evaporation at the annual time scale as well. In this case, the Proportionality Hypothesis dictates that the ratio of continuing evaporation to its potential value is equal to the ratio of runoff to its potential value. The Budyko Curve could then be seen as the straightforward outcome of the application of the Proportionality Hypothesis to estimate mean annual water balance. In this paper, we go further and demonstrate that the Proportionality Hypothesis itself can be seen as a result of the application of the thermodynamic principle of Maximum Entropy Production (MEP). In this way, we demonstrate a possible thermodynamic basis for the Proportionality Hypothesis, and consequently for the Budyko Curve. As a further extension, the L'vovich formulation for the two-stage partitioning of annual precipitation is also demonstrated to be a result of MEP: one for the competition between soil wetting and fast flow during the first stage; another for the competition between evaporation and base flow during the second stage.
\end{abstract}

\section{Introduction}

The Budyko Curve for mean annual water balance is an empirical result that is based on observations from around the world [Budyko, 1974]. The novel feature of the Budyko Curve is that mean annual water balance is represented in the form of a competition between water availability and energy availability [Roderick and Farquhar, 2011; Li et al., 2014]. Water availability is represented by annual precipitation and energy availability is often represented (for simplicity) by annual potential evaporation. However, the role of landscape properties on mean annual water balance is mainly implicit, and is deemed as being subservient to the dominant role of climate, which is explained by the coevolution and codependence of landscape properties with climate. In some formulations of the Budyko Curve, the role of the landscape is represented by a separate, lumped parameter [Mezentsev, 1955; Fu, 1981; Zhang et al., 2001; Donohue et al., 2007; Yang et al., 2008], which is nevertheless estimated empirically. In spite of the widespread use of the Budyko Curve, the connection between the simplicity of its functional form to the complexity of land surface and event scale processes has remained a long-standing, open question in hydrology.

Recently, Wang and Tang [2014] derived a new formulation of the Budyko Curve through application, to mean annual water balance, of a generalization of the so-called Proportionality Hypothesis found to underpin the Soil Conservation Service (SCS) curve number method used for computing direct runoff at the event scale [U.S. Department of Agriculture Soil Conservation Service (SCS), 1972]. In this case, as an analog to the concept of initial abstraction in the SCS method, annual evaporation was separated into an initial evaporation and continuing evaporation. The competition between continuing evaporation and runoff was then
(C) 2015. American Geophysical Union. All Rights Reserved. 
quantified by a generalized Proportionality Hypothesis, i.e., that the ratio of continuing evaporation to its potential value was equal to the ratio of runoff to its potential value. The potential value of the continuing evaporation is the difference between potential evaporation and initial evaporation; whereas the potential value of runoff is the water available for the competition, i.e., the difference between precipitation and initial evaporation. Indeed, a deeper finding of Wang and Tang [2014] was the demonstration of the existence and applicability of the Proportionality Hypothesis for characterizing precipitation partitioning at the event, seasonal, and annual time scales.

The aim of this technical note is to demonstrate that the Proportionality Hypothesis itself can be viewed as the outcome of the implementation of the Maximum Entropy Production (MEP) principle, viewed as a specific manifestation of the second law of thermodynamics. This has the effect of providing a thermodynamic basis for the Proportionality Hypothesis and by extension for the Budyko Curve as well. The existence of such a thermodynamic basis has profound implications for hydrology, in that it gives us the confidence to invoke MEP to address other fundamental problems in hydrological modeling, including especially the development of closure relations at the catchment scale in a parsimonious way, and the reduction of equifinality in model structures and associated parameterizations [Reggiani et al., 1999; Beven, 2006a; Schaefli et al., 2011].

\section{Proportionality Hypothesis and the Budyko Curve}

\subsection{Proportionality Hypothesis}

The Proportionality Hypothesis was proposed by Wang and Tang [2014] to express the symmetry they identified in empirical functional representations of precipitation at the event, seasonal and annual time scales. For example, at the event scale, rainfall is partitioned into direct runoff and soil wetting, where soil wetting includes both initial abstraction and continuing abstraction. The continuing abstraction can be deemed to be bounded by its capacity, i.e., the maximum or potential retention in the landscape, while the maximum or potential value for direct runoff is the available water, as quantified by the difference between rainfall and initial abstraction. In this case, the Proportionality Hypothesis dictates that the ratio of continuing abstraction to its potential value is equal to the ratio of direct runoff to its own potential value [SCS, 1972]. We note in passing that while the functional form of the SCS Curve Number method used here to recognize the Proportionality Hypothesis may be empirical, a process connection can be easily ascribed to it, e.g., through the application of the Green-Ampt infiltration model to infiltration and runoff generation during a rainfall event of finite duration and constant rainfall intensity (details left out for brevity).

One can extend the focus to the partitioning of annual precipitation into its runoff and evaporation components, and the variability of this partitioning between different years. L'vovich [1979] presented a functional model of this as a two-stage partitioning (see also Sivapalan et al. [2011] for more details). During the first stage, precipitation is partitioned into soil wetting and fast runoff; during the second stage, the soil wetting resulting from the first stage partitioning is further partitioned into evaporation and slow runoff. Ponce and Shetty [1995] recognized a similarity of the functional forms used for computing fast and slow runoff components at the annual scale (i.e., in the L'vovich [1979] formulation) with that used for computing direct runoff at the event scale using the SCS Curve Number method. This similarity with the SCS Curve Number method then allowed Sivapalan et al. [2011] and Wang and Tang [2014] to ascribe, through induction, a form of the Proportionality Hypothesis to the two-stage partitioning of annual precipitation, although the physical or process basis for this is yet to be established.

\subsection{Long-Term Mean Water Balance and the Budyko Curve}

Finally, we come to the special case of mean annual water balance and the Budyko Curve. Here we consider the partitioning of precipitation $(P)$ into evaporation $(E)$ and runoff $(Q)$, all of which are mean values over a long period of time, with negligible soil water storage change. A conceptual model of the partitioning of long-term mean precipitation into its components is shown in Figure 1. A fraction of precipitation is evaporated without any competition with runoff, which Wang and Tang [2014] denoted as initial evaporation $\left(E_{0}\right)$. Note that initial evaporation in the sense it is used here is broadly defined to include evaporation from leaf interception, from the forest floor, and from temporary storage in pools [Savenije, 2004]. Therefore, $P-E_{0}$ is defined as the effective precipitation, which is then partitioned into runoff and continuing (i.e., moisture constrained) evaporation $\left(E_{c}\right)$. The sum of $E_{0}$ and $E_{c}$ is total evaporation $(E)$. Since initial evaporation already 


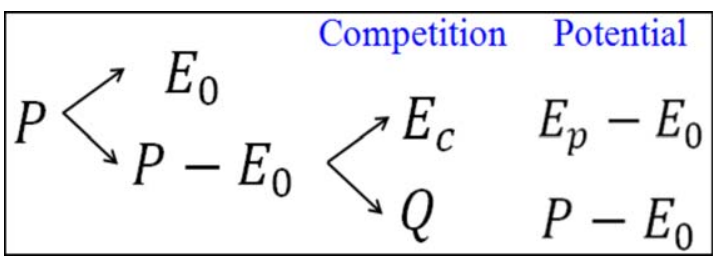

Figure 1. Diagram showing the effective precipitation $\left(P-E_{0}\right)$, the competition between continuing evaporation $\left(E-E_{0}\right)$ and runoff $(Q)$, and the corresponding potential values for continuing evaporation and runoff. meets a part of the evaporation demand (i.e., potential evaporation denoted here as $E_{p}$ ), $E_{p}-E_{0}$ is then defined as the effective potential evaporation.

Wang and Tang [2014] then implemented the Proportionality Hypothesis, in the sense outlined in the earlier two cases (i.e., event and annual), to long-term mean water balance partitioning presented in Figure 1. The potential value for runoff is the available water for competition, i.e., $P-E_{0}$. Based on the Proportionality Hypothesis, the ratio of continuing evaporation to its potential value is then deemed as being equal to the ratio of runoff to its potential value:

$$
\frac{E-E_{0}}{E_{p}-E_{0}}=\frac{P-E}{P-E_{0}}
$$

If the potential values are interpreted as the water demands by the atmosphere and the river, respectively, the meaning of equation (1) would be that the precipitation partitioning meets the same fraction of their water demands through continuing evaporation and runoff. Wang and Tang [2014] then demonstrated that a one-parameter Budyko-type equation can be derived in a straightforward manner from equation (1), as follows:

$$
\frac{E}{P}=\frac{1+E_{p} / P-\sqrt{\left(1+E_{p} / P\right)^{2}-4 \varepsilon(2-\varepsilon) E_{p} / P}}{2 \varepsilon(2-\varepsilon)}
$$

where $\varepsilon$ is a parameter $\left(\varepsilon=\frac{\gamma}{H}\right)$, defined as the ratio between the initial evaporation ratio $\left(\gamma=\frac{E_{0}}{W}\right.$ where $W$ is soil wetting) and the Horton index $\left(H=\frac{E}{W}\right)$ (see Troch et al. [2009] for details on the physical meaning of $H$ ). As a result, $\varepsilon$ can also be interpreted as $\frac{E_{0}}{E}$ and it happens that the range of $\varepsilon$ is between 0 and 1 . Equation (2) satisfies the essential boundary condition of the Budyko Curve: $\frac{E}{P} \rightarrow 0$ as $\frac{E_{p}}{P} \rightarrow 0$ and $\frac{E}{P} \rightarrow 1$ as $\frac{E_{p}}{P} \rightarrow \infty$. Also, it so happens that equation (2) has the same functional form as the "abcd model" for monthly water balance developed by Thomas [1981]. The net result of all this is that the derivation of the Budyko-type equation (2), as shown above, clearly demonstrates a linkage between the generalized Proportionality Hypothesis and the Budyko Curve, giving an alternative interpretation of the latter.

\section{Optimality Principle Behind the Proportionality Hypothesis: Maximum Entropy Production}

Both the Proportionality Hypothesis and the Budyko Curve are emergent patterns, both derived from analysis of observed data from a large population of watersheds based on analysis that would be deemed as fitting the Darwinian analysis approach [Harman and Troch, 2014]. These observed patterns call for an underlying organizing principle in order to go beyond mere (empirical) patterns to the underlying processes or mechanisms. The objective of this paper is to identify an optimality principle underpinning the Budyko Curve and also the L'vovich formulation [L'vovich, 1979] that describes annual precipitation partitioning as a two-stage competition; this would thus represent a synthesis of the Newtonian and Darwinian approaches, as called for by Harte [2002].

As a result of combining the first and second laws of thermodynamics, the Carnot limit describes the maximum rate of mechanical work (i.e., power) extracted from a heating source [Kleidon and Renner, 2013]. Power describes the generation of free energy which is dissipated into heat, resulting in entropy production. The maximum power limit constrains the dynamics of any given system, be it a biological system [Lotka, 1992a, 1992b], an environmental system [Kleidon et al., 2010], or a hydrologic system [Kleidon and Schymanski, 2008]. The underlying hypothesis is that systems that evolve to their thermodynamic limits are close to a state at which entropy production is maximized. The principle of Maximum Entropy Production (MEP) was originally formulated in the atmospheric sciences [Paltridge, 1975, 1979]. MEP is an organizing principle that potentially unifies biological and physical processes in natural systems [Dewar, 2010]. This thermodynamic principle can be applied to a watershed, considered as an open system that exchanges 
water with the atmosphere and the channel network [Westhoff et al., 2014]. The theoretical framework proposed by Kleidon and Schymanski [2008] for quantifying entropy production as part of the global hydrologic cycle is adapted in this study for catchment-scale long-term water balances.

\subsection{Entropy Production of Long-Term Water Balance}

In the long term, the total entropy production of a hydrologic system includes three components: entropy production associated with initial evaporation $\left(\sigma_{e 0}\right)$, and those associated with continuing evaporation $\left(\sigma_{e c}\right)$ and runoff $\left(\sigma_{r}\right)$. Following the flux-force trade-off framework for land surface hydrologic fluxes proposed by Kleidon and Schymanski [2008], evaporation is driven by the difference between the chemical potential of soil water, $\mu_{s}$ and the chemical potential for vegetation water $\left(\mu_{e}\right)$ [Westhoff et al., 2014]:

$$
E=k_{e}\left(\mu_{s}-\mu_{e}\right)
$$

where $k_{e}$ is a transfer coefficient for the soil-vegetation flux; chemical potential represents the sum of all relevant potentials, including matric potential, gravitational potential, and osmotic potentials. Similarly, the initial evaporation is driven by the difference of chemical potentials:

$$
E_{0}=k_{e i}\left(\mu_{s}-\mu_{e}\right)
$$

where $k_{e i}$ is a transfer coefficient for initial evaporation. Here the chemical potentials for water in the soil, surface retention, and canopy interception are assumed to be equal. Subtracting equation (4) from equation (3), one obtains:

$$
E-E_{0}=k_{e c}\left(\mu_{s}-\mu_{e}\right)
$$

where $k_{e c}=k_{e}-k_{e i}$, which is the transfer coefficient for continuing evaporation. Likewise, runoff is driven by the difference between $\mu_{s}$ and the chemical potential of the water when it reaches the river channel $\left(\mu_{r}\right)$, and can similarly be expressed as:

$$
Q=k_{r}\left(\mu_{s}-\mu_{r}\right)
$$

where $k_{r}$ is a runoff transfer coefficient and $\mu_{r}$ is the gravitational potential at the height of the river channel.

The optimized values of $k_{e}$ and $k_{r}$ obtained by Porada et al. [2011] based on implementation of MEP were different by orders of magnitude. Westhoff et al. [2014] demonstrated that climate seasonality can result in climate-dependent optimal transfer coefficients. Therefore, both $k_{e}$ and $k_{r}$ are controlled by climatic driving forces. In this paper, for simplicity, it is assumed that $k_{e c}$ in equation (5) is proportional to the effective potential evaporation because the process is driven by the effective atmospheric water demand:

$$
k_{e c}=\alpha_{e c}\left(E_{p}-E_{0}\right)
$$

where $\alpha_{e c}$ is a coefficient that represents the conductance (inverse of resistance) of continuing evaporation. The conductance for continuing evaporation increases with effective potential evaporation. Similarly, the runoff transfer coefficient is assumed to be proportional to the effective precipitation, based on the argument that wetter soils (e.g., soils wetted by rainfall) conduct water better than drier soils:

$$
k_{r}=\alpha_{r}\left(P-E_{0}\right)
$$

where $\alpha_{r}$ is a coefficient that represents runoff conductance. The resistance for runoff increases with decreasing effective precipitation.

Equations (7) and (8) are clearly underpinned by simplifying, admittedly expedient assumptions. However, these assumptions can be shown to be consistent with standard parameterizations used for soil moisture controlled evaporation and runoff in many conceptual (and even physically based) hydrological models. For example, the gradient of water chemical potential $\left(\mu_{s}-\mu_{e}\right)$ can be notionally related to catchment water storage (S). Combining equations (5) and (7) leads to an equation similar to $E \propto E_{p} \cdot f(S)$, where $f(S)$ is a function of soil moisture. This is indeed the approach usually adopted for soil moisture controlled evaporation in process-based hydrologic models. Likewise, the gradient of water chemical potential $\left(\mu_{s}-\mu_{r}\right)$ can be notionally related to storage, $S$. Then, combining equation (6) with equation (8) leads to $Q=\alpha_{r} \cdot\left(\mu_{s}-\mu_{r}\right) \cdot\left(P-E_{0}\right)$. The chemical potential of soil water $\left(\mu_{s}\right)$ is taken to be proportional to storage $(S)$, 
and $\mu_{r}$ is assumed to be zero [Westhoff et al., 2014]. The functional relationship between runoff and storage is usually nonlinear [e.g., Wittenberg, 1999]. Therefore, the combination of equation (6) and equation (8) leads to $Q=\alpha_{r} \cdot S \cdot g(S)$ where $g(S)$ includes precipitation and other factors. In other words, the adoption of equation (8) is equivalent to the adoption of a nonlinear storage-discharge relationship in traditional process-based hydrological models.

Even though, as mentioned above, equations (7) and (8) are consistent with standard parameterizations in many conceptual and physically based hydrological models, future research is required to verify these assumptions using direct observations. For this purpose, initial evaporation and continuing evaporation and corresponding water storages in a catchment will need to be measured, on the basis of which conductance coefficients for evaporation and runoff could be computed. This is left for future research.

The entropy production for continuing evaporation and runoff are now evaluated for quantifying the total entropy production of the hydrologic system. Entropy production is computed as the product of the mass flux across the boundaries and the gradient of chemical potential, divided by the temperature at which the processes take place [Kondepudi and Prigogine, 1998]. Following the expressions for entropy production proposed by Kleidon and Schymanski [2008], the entropy production rates associated with continuing evaporation and runoff are represented, respectively, by the following equations:

$$
\begin{gathered}
\sigma_{e c}=\rho k_{e c} \frac{\left(\mu_{s}-\mu_{e}\right)^{2}}{T} \\
\sigma_{r}=\rho k_{r} \frac{\left(\mu_{s}-\mu_{r}\right)^{2}}{T}
\end{gathered}
$$

where $\rho$ is the density of water and $T$ is the temperature at which the process occurs. Substituting equations (5) and (7) into equation (9) and considering entropy production by initial evaporation, the entropy production by evaporation process, $\sigma_{e}$, is expressed as:

$$
\sigma_{e}=\frac{\rho\left(E-E_{0}\right)^{2}}{T \alpha_{e c}\left(E_{p}-E_{0}\right)}+\sigma_{e 0}
$$

Similarly, the entropy production by the runoff process, $\sigma_{r}$, is obtained by substituting equations (6) and (8) into equation (10):

$$
\sigma_{r}=\frac{\rho Q^{2}}{T \alpha_{r}\left(P-E_{0}\right)}
$$

\subsection{Maximum Entropy Production and Proportionality Hypothesis}

The total entropy production of the hydrologic system is then expressed as:

$$
\sigma_{\text {system }}=\sigma_{e 0}+\frac{\rho}{T}\left[\frac{\left(E-E_{0}\right)^{2}}{\alpha_{e c}\left(E_{p}-E_{0}\right)}+\frac{Q^{2}}{\alpha_{r}\left(P-E_{0}\right)}\right]
$$

For a given watershed, $\frac{\rho}{T}$ can be treated as a constant; note that the volume of water associated with $E_{0}$ is not considered to be part of the competition with runoff, and the corresponding entropy production $\left(\sigma_{e 0}\right)$ is then treated as a constant. The entropy production by continuing evaporation and runoff processes is dependent on the competition between $E_{c}$ and $Q$. As a result, the implementation of MEP to this system can be formulated as the following optimization problem:

$$
\begin{gathered}
\text { Max : } \sigma_{\text {system }}(E, Q)=\left[\frac{\left(E-E_{0}\right)^{2}}{\alpha_{e c}\left(E_{p}-E_{0}\right)}+\frac{Q^{2}}{\alpha_{r}\left(P-E_{0}\right)}\right] \\
\text { subject to }: P=E+Q
\end{gathered}
$$

where the decision variables in the optimization are evaporation $(E)$ and runoff $(Q)$ and the constraint is long-term mean water balance. Note that in the studies by Kleidon and Schymanski [2008] and Westhoff et al. [2014], the optimal value of $k_{e}$ was determined by maximizing the entropy production of evaporation and the optimal value of $k_{r}$ was determined separately by maximizing the entropy production of runoff. 
However, in this paper, runoff and evaporation are estimated together by maximizing total entropy production due to both evaporation and runoff under given values of $\alpha_{e c}$ and $\alpha_{r}$, i.e., $Q$ and $E$ are taken as the decision variables. The total entropy production of runoff and evaporation is maximized since these two processes are interconnected. The mean annual water balance in the Budyko framework is formulated as the competition between evaporation and runoff given available water and energy supply. Under the condition of $\alpha_{e c}=0$ and $\alpha_{r}=0$, runoff and continuing evaporation both approach zeros for $E_{0}=P$. The corresponding $\sigma_{\text {system }}$ is a constant of $\sigma_{e 0}$.

The optimization problem presented in equation (14) can be solved by applying the method of Lagrange multipliers:

$$
\operatorname{Max}: f(E, Q, \lambda)=\frac{\left(E-E_{0}\right)^{2}}{\alpha_{e c}\left(E_{p}-E_{0}\right)}+\frac{Q^{2}}{\alpha_{r}\left(P-E_{0}\right)}+\lambda(P-E-Q)
$$

For a given watershed, $\sigma_{e c}$ and $\alpha_{r}$ are independent of $E$ and $Q$ since they are nominally watershed properties. The role of soil water storage on $E$ is already reflected in the chemical potential of soil moisture in equation (5); and the role of soil water storage change on $Q$ is already reflected in the chemical potential of soil moisture presented in equation (6) and precipitation in equation (8). Then, the optimal solution is obtained by setting the partial derivatives of the objective function, $f(E, Q$, $\lambda)$, equal to zeros:

$$
\begin{gathered}
\frac{\partial f}{\partial E}=\frac{2\left(E-E_{0}\right)}{\alpha_{e c}\left(E_{p}-E_{0}\right)}-\lambda=0 \\
\frac{\partial f}{\partial Q}=\frac{2 Q}{\alpha_{r}\left(P-E_{0}\right)}-\lambda=0 \\
\frac{\partial f}{\partial \lambda}=P-E-Q=0
\end{gathered}
$$

Substituting $\lambda$ in equation (16-1) and $Q$ in equation (16-3) into equation (16-2), one obtains:

$$
\frac{\left(E-E_{0}\right)}{\alpha_{e c}\left(E_{p}-E_{0}\right)}=\frac{P-E}{\alpha_{r}\left(P-E_{0}\right)}
$$

Comparing equations (1) and (17), one can see that the generalized Proportionality Hypothesis can indeed be seen as the outcome of the MEP principle, provided there is a similarity between the continuing evaporation and runoff transfer coefficients (i.e., $\alpha_{e c}=\alpha_{r}$ ). Therefore, by extension, the principle of MEP provides a theoretical foundation to understand the empirical Budyko Curve, since Wang and Tang [2014] have already shown that the Budyko Curve (equation (2)) can also be seen as an outcome of the Proportionality Hypothesis.

One can of course question the existence of such a similarity, i.e., $\alpha_{e c}=\alpha_{r}$. Let us therefore consider a weaker version of the Proportionality Hypothesis, where the values of $\alpha_{e c}$ and $\alpha_{r}$ are allowed to remain unequal. Let the ratio between $\alpha_{e c}$ and $\alpha_{r}$ be denoted as $\phi$, i.e., $\phi=\alpha_{e c} / \alpha_{r}$. Following the procedure of Wang and Tang [2014], a two-parameter Budyko-type equation can still be derived from equation (17):

$$
\frac{E}{P}=\frac{1+\phi \varepsilon-\varepsilon+\phi \frac{E_{p}}{P} \sqrt{\left(1+\phi \varepsilon-\varepsilon+\phi \frac{E_{p}}{P}\right)^{2}-4 \phi \varepsilon(1+\phi-\varepsilon) \frac{E_{p}}{P}}}{2 \varepsilon(1+\phi-\varepsilon)}
$$

When $\varphi=1$, equation (18) is indeed identical to equation (2). Figure 2 presents plots of equation (16-) for the cases: (1) $\phi=1$ and $\varepsilon=0.6$ and (2) $\phi=0.7$ and $\varepsilon=0.6$. It should be noted that not all the combinations of $\phi$ and $\varepsilon$ satisfy the upper limit of E/P associated with the Budyko Curve, i.e., $\phi$ and $\varepsilon$ are actually interdependent. The resulting formulation is only slightly different from many one-parameter formulations already used in the literature [e.g., Fu, 1981; Zhang et al., 2001; Yang et al., 2008]. Here it is shown that the Budyko formulation is derivable from the Proportionality Hypothesis, which in turn can be derived through application of the principle of MEP. In this way, the Budyko formulation for mean annual water balance is shown to be a manifestation of the principle of MEP. 


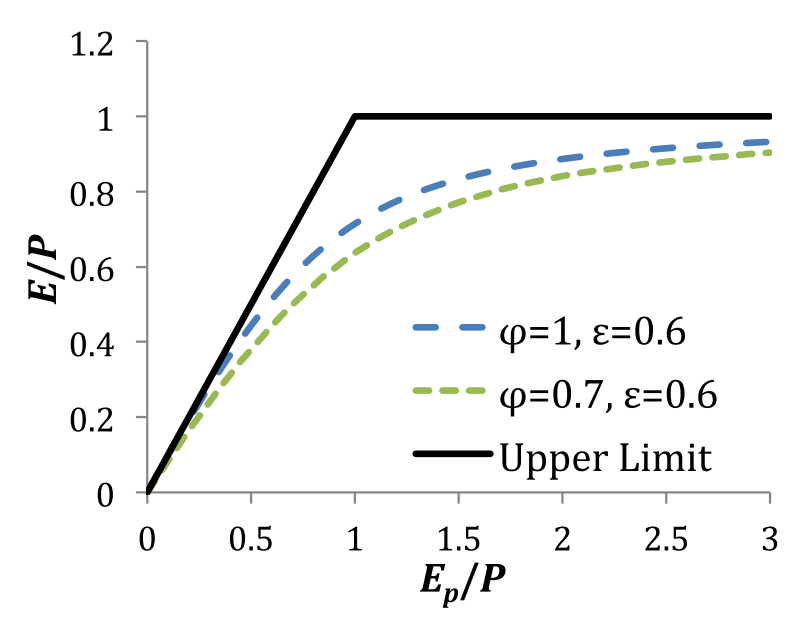

Figure 2. Two-parameter ( $\phi$ and $\varepsilon$ ) Budyko-type equation obtained from a weak version of the Proportionality Hypothesis.
The outcomes obtained here by maximizing entropy production are for a hydrologic system that is close to the state of its thermodynamic limit. The thermodynamic limit for evaporation is related to the ability of atmospheric motion to remove moist air near the surface [Kleidon and Renner, 2013]. The extent of atmospheric exchange that drives evaporation is constrained by the maximum power limit. Runoff is driven by the depletion of potential energy in the catchment, and its conversion to kinetic energy, which either is exported from the catchment by performing work on sediments, or is dissipated by friction. The thermodynamic limit for runoff is likely to be the maximum rate of sediment transport that would deplete topographic gradients at the fastest possible rate [Kleidon et al., 2013]. Even though the thermodynamic limit is not directly linked to the evaporative flux and runoff, the maximum power limit is approximately equivalent with maximum entropy production [Kleidon et al., 2013; Kleidon and Renner, 2013].

\section{Extension to L'vovich Formulation}

Annual precipitation partitioning is described as a two-stage competition in the L'vovich formulation [ $L$ 'vovich, 1979]. Precipitation is partitioned into soil wetting $(W)$ and fast runoff $\left(Q_{f}\right)$ in the first stage of the competition. After the initial soil wetting $\left(W_{0}\right)$ is met, continuing wetting $\left(W-W_{0}\right)$ and fast runoff compete for the available water of $\left(P-W_{0}\right)$. The potential (maximum) value of continuing wetting is the remaining wetting capacity, $W p-W_{0}$, where $W p$ is the wetting capacity. The potential (maximum) value of fast runoff is the available water, i.e., $P-W_{0}$. The continuing wetting is driven by the difference between the chemical potential of precipitation $\left(\mu_{p}\right)$ and the chemical potential of soil moisture:

$$
W-W_{0}=k_{w}\left(\mu_{p}-\mu_{s}\right)
$$

where $k_{w}$ is a transfer coefficient for the wetting. The conductance for wetting increases with its capacity, and $k_{w}$ is assumed to be proportional to continuing wetting capacity:

$$
k_{w}=\alpha_{w}\left(W_{p}-W_{0}\right)
$$

Fast runoff is driven by the difference between the chemical potential of soil water and the chemical potential of the water when it reaches the river channel:

$$
Q_{f}=k_{f}\left(\mu_{s}-\mu_{r}\right)
$$

where $k_{f}$ is the direct runoff transfer coefficient. The conductance for fast flow is assumed to be proportional to its potential:

$$
k_{f}=\alpha_{f}\left(P-W_{0}\right)
$$

The application of the MEP principle to the first stage of precipitation partitioning is equivalent to the following optimization problem:

$$
\begin{gathered}
\operatorname{Max} \sigma_{\text {stage } 1}\left(W, Q_{f}\right)=\frac{\left(W-W_{0}\right)^{2}}{\alpha_{W}\left(W_{p}-W_{0}\right)}+\frac{Q_{f}^{2}}{\alpha_{f}\left(P-W_{0}\right)} \\
\text { subject to } P=W+Q_{f}
\end{gathered}
$$

After applying the method of Lagrange multipliers, we obtain the optimal solution: 


$$
\frac{W-W_{0}}{\alpha_{w}\left(W_{p}-W_{0}\right)}=\frac{P-W}{\alpha_{f}\left(P-W_{0}\right)}
$$

If $\alpha_{w}=\alpha_{f}$, equation (24) becomes the statement of the Proportionality Hypothesis for the first stage partitioning; if $\alpha_{w} \neq \alpha_{f}$, a weaker version of the Proportionality Hypothesis will be obtained.

In the second stage of precipitation partitioning, wetting is partitioned into evaporation and slow flow $\left(Q_{s}\right)$. After the initial evaporation $\left(E_{0}\right)$ is met, continuing evaporation $\left(E-E_{0}\right)$ and fast runoff compete for the available water of $\left(W-E_{0}\right)$. The potential (maximum) value of continuing evaporation is $E_{p}-E_{0}$. The potential (maximum) value of slow flow is the available water $\left(W-E_{0}\right)$. The conductance for continuing evaporation is assumed to be proportional to its potential value, as in equation (7). The conductance for slow flow is assumed to be proportional to its potential value:

$$
k_{s}=\alpha_{s}\left(W-E_{0}\right)
$$

By applying the MEP principle, the optimal solution for the second stage of precipitation partitioning is obtained:

$$
\frac{E-E_{0}}{\alpha_{e c}\left(E_{p}-E_{0}\right)}=\frac{W-E}{\alpha_{s}\left(W-E_{0}\right)}
$$

If $\alpha_{e c} \neq \alpha_{s}$, a weaker version of Proportionality Hypothesis will be obtained; if $\alpha_{e c}=\alpha_{s}$, then equation (26) becomes the statement of the Proportionality Hypothesis for the second stage partitioning. Therefore, the L'vovich formulation involves the application of two Proportionality Hypotheses for the first and second stages of partitioning, both of which can be derived from the MEP principle.

\section{Summary and Broader Implications}

Hydrologic predictions in space and time are challenging due to the difficulty in choosing the appropriate mapping between the physical (biological and geomorphologic) structure of the watershed system and the necessary model structure to represent the dominant hydrologic processes. Both upward (bottom-up) and downward (top-down) approaches have been proposed and tried for building a suite of hydrologic models [Sivapalan et al., 2003]. Bottom-up methods rely on the detailed physical descriptions of all relevant processes and their interactions to predict the watershed response as a whole. On the other hand, top-down methods focus on identifying emergent patterns at the large scale from observed integral responses, and then identifying the dominant processes and their interactions that may have given rise to these. Bottomup models suffer from the fact that the observations on physical (biological and geomorphologic) structures and associated hydrologic processes are usually not available in the entire watershed to underpin these. On the other hand, top-down models suffer from the equifinality issue due to their limited physical basis, i.e., several model structures and associated model parameters may yield the same watershed responses [Beven, 2006b]. A synthesis of the two modeling approaches stands a better chance at maximizing the strengths both approaches offer, while minimizing their weaknesses.

A possible way to resolve the model development dilemma posed above is to use an intermediate level of abstraction for developing model structures and the characterization of landscape heterogeneity and process complexity. In this sense, the concept of watershed or ecosystem function has been suggested as a way forward [Sivapalan, 2005; McDonnell et al., 2007]. The ecosystem functions of a watershed, which might include partitioning, storage, and release of water, are emergent behaviors arising from the natural organization of the watershed structure, including the codependence of climate, soil, topography, and vegetation [Schaefli et al., 2011]. The existence of a natural organizing principle may provide a theoretical framework to understand these collective watershed functions, and in turn may be used to constrain the diverse model structures and parameterizations that may otherwise equally well reproduce the overall system behavior [Ehret et al., 2014].

Hydrologists have been on the lookout for an organizing principle that might underpin predictions and reduce the equifinality of such predictions [McDonnell et al., 2007; Schaefli et al., 2011], and a range of organization principles have been proposed. The organizing principles so far proposed are based either on a piori knowledge or theories derived from the constituent physical and ecological sciences, and/or are 
inferred from empirically observed patterns of watershed responses. Examples include ecological optimality based on minimization of water stress [Eagleson, 1982], or a more general form of vegetation optimality based on maximization of net carbon profit [Schymanski et al., 2007], minimum energy expenditure [Rodríguez-Iturbe et al., 1992], maximum energy dissipation [Zehe et al., 2010], and maximum entropy production [Kleidon and Schymanski, 2008; Paik and Kumar, 2010; del Jesus et al., 2012].

However, all of these principles are externally imposed-coming into hydrology from ecology (vegetation or ecological optimality), physics (minimum energy expenditure), or thermodynamics (maximum entropy production). Can such organizing principles be internally generated-or discovered-directly from the analysis of observed hydrologic responses? The Budyko Curve is an example of a widely accepted, universal but empirical pattern derived entirely from within the hydrological realm, and has indeed been suggested as an empirical organizing principle [Schaefli et al., 2011]. Is it in any way related to, or derivable from, any of the external or more universal optimality principles mentioned above? This paper has been motivated by this long-standing question. In this paper, we have demonstrated that the Proportionality Hypothesis underpinning long-term mean water balance, and by extension, the Budyko Curve, are indeed consistent with, and derivable from, the optimality principle of Maximum Entropy Production.

These results have broader implications. The application of the MEP principle here to long-term mean water balance gives hope and guidance to other attempts to discover universal patterns in watershed response observations. More importantly, the existence of such an organizing principle gives hope to attempt to constrain model parameterizations for many internal hydrologic processes for which no equivalent data exists. For example, Li et al. [2014] demonstrated that the Budyko Curve could be used to constrain the interdependence of climate, soil, and topography parameter combinations, and revealed the linkage between Budyko Curve and the Dunne diagram. This gives hope that the MEP principle can be used to constrain hydrologic model parameters through its linkage with the Budyko Curve as an organizational pattern of hydrologic system responses. This is left for further research.

\section{Acknowledgments}

This research was funded in part by the NASA Kennedy Space Center, Ecological Program, Climate Adaptation Science Investigators (CASI) project (award: IHA-SA-13-006). The paper benefited from insightful comments from Hubert Savenije, Michael Roderick, Peter Troch, Axel Kleidon, Martijn Westhoff, Bettina Schaefli, Stan Schymanski, and Ciaran Harman, for which we are grateful. No data were used in producing this manuscript.

\section{References}

Beven, K. (2006a), Searching for the Holy Grail of scientific hydrology: $Q_{t}=(S, R, \Delta t) A$ as closure, Hydrol. Earth Syst. Sci., 10, 609-618, doi: 10.5194/hess-10-609-2006.

Beven, K. (2006b), A manifesto for the equifinality thesis, J. Hydrol., 320, 18-36.

Budyko, M. I. (1974), Climate and Life, 508 pp., Academic, N. Y.

del Jesus, M., R. Fotia, A. Rinaldo, and I. Rodriguez-Iturbe (2012), Maximum entropy production, carbon assimilation, and the spatial organization of vegetation in river basins, Proc. Natl. Acad. Sci. U. S. A., 109, 20,837-20,841.

Dewar, R. C. (2010), Maximum entropy production and plant optimization theories, Philos. Trans. R. Soc. B, 365(1545), 1429-1435, doi: 10.1098/rstb.2009.0293.

Donohue, R. J., M. L. Roderick, and T. R. McVicar (2007), On the importance of including vegetation dynamics in Budyko's hydrological model, Hydrol. Earth Syst. Sci., 11, 983-995, doi:10.5194/hess-11-983-2007.

Eagleson, P. S. (1982), Ecological optimality in water-limited natural soil-vegetation systems: 1. Theory and hypothesis, Water Resour. Res., 18(2), 325-340, doi:10.1029/WR018i002p00325.

Ehret, U., et al. (2014), Advancing catchment hydrology to deal with predictions under change, Hydrol. Earth Syst. Sci., 18, 649-671, doi: 10.5194/hess-18-649-2014.

Fu, B. P. (1981), On the calculation of the evaporation from land surface [in Chinese], Sci. Atmos. Sin., 5(1), $23-31$.

Harman, C., and P. A. Troch (2014), What makes Darwinian hydrology "Darwinian"? Asking a different kind of question about landscapes, Hydrol. Earth Syst. Sci., 18, 417-433, doi:10.5194/hess-18-417-2014.

Harte, J. (2002), Toward a synthesis of the Newtonian and Darwinian worldviews, Phys. Today, 55, 29-35, doi:10.1063/1.1522164.

Kleidon, A., and M. Renner (2013), Thermodynamic limits of hydrologic cycling within the Earth system: Concepts, estimates and implications, Hydrol. Earth Syst. Sci., 17, 2873-2892.

Kleidon, A., and S. J. Schymanski (2008), Thermodynamics and optimality of the water budget on land: A review, Geophys. Res. Lett., 35, L20404, doi:10.1029/2008GL035393.

Kleidon, A., Y. Malhi, and P. M. Cox (2010), Maximum entropy production in environmental and ecological systems, Philos. Trans. R. Soc. B, 365, 1297-1302.

Kleidon, A., E. Zehe, U. Ehret, and U. Scherer (2013), Thermodynamics, maximum power, and the dynamics of preferential river flow structures at the continental scale, Hydrol. Earth Syst. Sci., 17, 225-251.

Kondepudi, D., and I. Prigogine (1998), Modern Thermodynamics: From Heat Engines to Dissipative Structures, John Wiley, Chichester, U. K.

Li, H., M. Sivapalan, F. Tian and C. Harman (2014), Functional approach to exploring climatic and landscape controls of runoff generation: 1. Behavioral constraints on runoff volume, Water Resour. Res., 50, 9300-9322, doi:10.1002/2014WR016307.

Lotka, A. J. (1992a), Contribution to the energetics of evolution, Proc. Natl. Acad. Sci. U. S. A., 8, 147-151.

Lotka, A. J. (1992b), Natural selection as a physical principle, Proc. Natl. Acad. Sci. U. S. A., 8, 151-154.

L'vovich, M. I. (1979), World Water Resources and Their Future, 415 pp., AGU, Washington, D. C.

McDonnell, J. J., et al. (2007), Moving beyond heterogeneity and process complexity: A new vision for watershed hydrology, Water Resour. Res., 43, W07301, doi:10.1029/2006WR005467.

Mezentsev, V. S. (1955), More on the calculation of average total evaporation, Meteorol. Gidrol., 5, 24-26. 
Paik, K., and P. Kumar (2010), Optimality approaches to describe characteristic fluvial patterns on landscapes, Philos. Trans. R. Soc. B, 365(1545), 1387-1395, doi:10.1098/rstb.2009.0303.

Paltridge, G. W. (1975), Global dynamics and climate-A system of minimum entropy exchange, Q. J. R. Meteorol. Soc., 101, $475-484$. Paltridge, G. W. (1979), Climate and thermodynamic systems of maximum dissipation, Nature, 279, 630-631.

Ponce, V. M., and A. V. Shetty (1995), A conceptual model of catchment water balance. 1. Formulation and calibration, J. Hydrol., 173, 27-40.

Porada, P., A. Kleidon, and S. J. Schymanski (2011), Entropy production of soil hydrological processes and its maximisation, Earth Syst. Dyn., 2(2), 179-190, doi:10.5194/esd-2-179-2011.

Reggiani, P., S. M. Hassanizadeh, M. Sivapalan, and W. G. Gray (1999), A unifying framework for watershed thermodynamics. Constitutive relationships. Adv. Water Resour., 23(1), 15-39.

Roderick, M. L., and G. D. Farquhar (2011), A simple framework for relating variations in runoff to variations in climatic conditions and catchment properties, Water Resour. Res., 47, W00G07, doi:10.1029/2010WR009826.

Rodríguez-Iturbe, I., A. Rinaldo, R. Rigon, R. L. Bras, A. Marani and E. Ijjász-Vásquez (1992), Energy dissipation, runoff production, and the three-dimensional structure of river basins, Water Resour. Res., 28(4), 1095-1103, doi:10.1029/91WR03034.

Savenije, H. H.G. (2004), The importance of interception and why we should delete the term evapotranspiration from our vocabulary, Hydrol. Processes, 18(8), 1507-1511.

Schaefli, B., C. J. Harman, M. Sivapalan, and S. J. Schymanski (2011), Hydrologic predictions in a changing environment: Behavioral modeling, Hydrol. Earth Syst. Sci., 15, 635-646.

Schymanski, S. J., M. L. Roderick, M. Sivapalan, L. B. Hutley, and J. Beringer (2007), A test of the optimality approach to modelling canopy properties and $\mathrm{CO}_{2}$ uptake by natural vegetation, Plant Cell Environ., 30(12), 1586-1598.

Sivapalan, M. (2005), Pattern, process and function: Elements of a new unified hydrologic theory at the catchment scale, in Encyclopedia of Hydrologic Sciences, vol. 1, Part 1, edited by M. G. Anderson, chap. 13, pp. 193-219, John Wiley, Hoboken, N. J.

Sivapalan, M., G. Blöschl, L. Zhang, and R. Vertessy (2003), Downward approach to hydrological prediction, Hydrol. Processes, 17(11), 2101-2111.

Sivapalan, M., M. A. Yaeger, C. J. Harman, X. Xu, and P. A. Troch (2011), Functional model of water balance variability at the catchment scale: 1. Evidence of hydrologic similarity and space-time symmetry, Water Resour. Res., 47, W02522, doi:10.1029/2010WR009568.

Thomas, H. A. (1981), Improved methods for national water assessment, water resource contract WR15249270, USGS unnumbered series, Harvard Water Resources Group. [Available at http://pubs.er.usgs.gov/publication/70046351.]

Troch, P. A., G. F. Martinez, V. R. N. Pauwels, M. Durcik, M. Sivapalan, C. J. Harman, P. D. Brooks, H. V. Gupta, and T. E. Huxman (2009), Climate and vegetation water-use efficiency at catchment scales, Hydrol. Processes, 23, 2409-2414, doi:10.1002/hyp.7358.

U.S. Department of Agriculture Soil Conservation Service (SCS) (1972), National Engineering Handbook, Section 4, Hydrology, U.S. Gov. Print. Off., Washington, D. C.

Wang, D., and Y. Tang (2014), A one-parameter Budyko model for water balance captures emergent behavior in Darwinian hydrologic models, Geophys. Res. Lett., 41, 4569-4577, doi:10.1002/2014GL060509.

Westhoff, M. C., E. Zehe, and S. J. Schymanski (2014), Importance of temporal variability for hydrological predictions based on the maximum entropy production principle, Geophys. Res. Lett., 41, 67-73, doi:10.1002/2013GL058533.

Wittenberg, H. (1999), Baseflow recession and recharge as nonlinear storage processes, Hydrol. Processes, 13, 715-726.

Yang, H., D. Yang, Z. Lei, and F. Sun (2008), New analytical derivation of the mean annual water-energy balance equation, Water Resour. Res., 44, W03410, doi:10.1029/2007WR006135.

Zehe, E., T. Blume, and G. Blöschl (2010), The principle of 'maximum energy dissipation': A novel thermodynamic perspective on rapid water flow in connected soil structures, Philos. Trans. R. Soc. B, 365(1545), 1377-1386, doi:10.1098/rstb.2009.0308.

Zhang, L., W. R. Dawes, and G. R. Walker (2001), Response of mean annual evapotranspiration to vegetation changes at catchment scale, Water Resour. Res., 37(3), 701-708, doi:10.1029/2000WR900325. 